\title{
Construção e validação de uma cartilha como tecnologia educacional para promoção da gestão socioambientalmente responsável de compras
}

\section{Josiane Tolêdo e Silva ${ }^{1}$ e André Yves Cribb ${ }^{2}$}

\author{
${ }^{1}$ Universidade Federal Rural do Rio de Janeiro. BR-465, km 07. Zona Rural. \\ Seropédica-RJ, Brasil (CEP 23890-000). E-mail: jojo-toledo@hotmail.com. \\ ${ }^{2}$ Empresa Brasileira de Pesquisa Agropecuária - EMBRAPA. Av. das Américas, \\ 29501. Guaratiba. Rio de Janeiro-RJ, Brasil (CEP 23020-470).
}

Resumo. À medida que aumenta a conscientização da população a respeito da adoção de ações sustentáveis, aumenta também a cobrança aos órgãos públicos por políticas ambientais eficientes. Embora exista legislação que trata da compra de itens sustentáveis na administração pública, os órgãos públicos ainda estão em fase de adequação e há uma baixa adesão dos servidores públicos por motivos diversos. Assim, este estudo tem como objetivo construir e validar uma tecnologia educacional no formato de cartilha com a finalidade de disseminar conhecimento a respeito da compra socioambientalmente responsável, utilizando ilustrações e linguagem de fácil compreensão. A pesquisa está dividida em três fases distintas e compreendeu um estudo de desenvolvimento metodológico através da abordagem de métodos mistos. Na primeira fase foi realizada uma revisão bibliográfica sistemática através da revisão integrativa e um diagnóstico situacional através de uma pesquisa exploratória com abordagem qualitativa que utiliza o questionário como ferramenta para a coleta de dados junto aos servidores do Instituto Federal de Educação, Ciência e Tecnologia do Rio de Janeiro com a finalidade de identificar as dificuldades apresentadas na realização de compras de itens sustentáveis. A segunda fase da pesquisa abrangeu a elaboração do conteúdo, das ilustrações, da aparência e da linguagem da cartilha intitulada "Vamos pensar no planeta? Um pequeno gesto pode fazer uma grande diferença". A terceira fase da pesquisa consistiu na validação da cartilha por quinze juízes de linguagem, conteúdo e aparência e posteriormente por dezesseis representantes do público alvo. Para tal utilizou-se a abordagem quantitativa através da Escala Likert. Pretende-se disponibilizar a cartilha por meios digitais.

Palavras-chave: Compras organizacionais; Administração pública; Tecnologia educacional; Responsabilidade socioambiental.

Recebido

$20 / 10 / 2020$

Aceito

$20 / 12 / 2020$

Disponível on line 23/12/2020

Publicado

$31 / 12 / 2020$

Acesso aberto

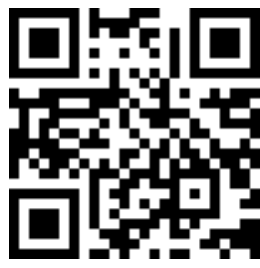

ORCID

(1) 0000-0002-7314-0122 Josiane Tolêdo e Silva

(D) 0000-0003-4243-394X André Yves Cribb

ISSN 2359-1412/RBGAS-2020-0155/2020/7/17/37/1619

Rev. Bras. Gest. Amb. Sustent.

http://revista.ecogestaobrasil.net 
Abstract. Development and validation of a booklet as an educational technology to promote socio-environmentally responsible purchasing management. As the population's awareness of adopting sustainable actions increases, so does the demand from public bodies for efficient environmental policies. Although there is legislation that deals with the purchase of sustainable items in the public administration, government agencies are still adapting to this context. Moreover, for various reasons, few civil servants have joined this sustainable measure. Thus, this study aimed to develop and validate an educational technology in the form of a booklet with the purpose of disseminating knowledge of socio-environmentally responsible purchasing, using illustrations and language that are easy to understand. This research was divided into three distinct phases and included a methodological study based on the approach of mixed methods. The first phase consisted of a systematic bibliographic review and a situational diagnosis tough an integrative review and exploratory research, respectively. The situational diagnosis was performed using a qualitative approach, applying a questionnaire to civil servants of the Federal Institute of Education, Science and Technology of Rio de Janeiro to identify their difficulties when purchasing sustainable items. The second phase comprised the elaboration of the content, illustrations, appearance, and language of the booklet entitled "Shall we think about the planet? A small gesture can make a big difference". The third phase consisted of the validation of the booklet by fifteen judges, who analyzed the product as for the language, content, and appearance, and later by sixteen representatives of the target audience. The Likert Scale was used for this quantitative approach. It is intended to make the booklet available digitally.

Keywords: Organizational purchase; Public administration; Educational technology; Purchasing management; Socio-environmental responsibility.

\section{Introdução}

No decorrer do século XX, o aumento da frequência de acidentes ambientais e da contaminação do meio ambiente despertou a sociedade e chamou a atenção da opinião pública para a proporção da degradação ambiental (Dias, 2006).

O desenvolvimento sustentável tornou-se um tema de grande repercussão mundial na atualidade, contudo, não apresenta uma solução simples e fácil de ser executada para resolver o desequilíbrio ambiental. Adequar o equilíbrio da demanda e do abastecimento é a grande questão ambiental e social, pois o limite do abastecimento é limitado enquanto que a demanda pode ser ilimitada (Penna, 1999).

Embora uma ação deva contemplar vários aspectos para ser considerada de fato sustentável, o tripé da sustentabilidade se mantém incontestável pelos autores da área como o caminho para alcançar a sustentabilidade. 0 tripé da sustentabilidade observa as ações sob três perspectivas a ser contempladas: social, econômica e ambiental.

A sustentabilidade pressupõe a definição de limites às possibilidades de crescimento, desta forma requer iniciativas que considerem os interlocutores e 
participantes sociais para desenvolver práticas educativas e construção de diálogo que busque a coresponsabilização e a construção de valores éticos, sem ignorar as dimensões culturais, as relações de poder existentes e o reconhecimento das limitações ecológicas, a fim de cessar esse padrão predatório de desenvolvimento (Jacobi, 2003).

Cada organização tem sua forma e intensidade de relação com o meio ambiente, ocasionando impactos de tipos e de intensidade distintos. Assim, a busca por ações transparentes tornou-se um grande diferencial competitivo e inovou a relação das empresas com o mercado e com a sociedade (Ashley et al., 2003).

Utilizar o marketing para positivar e divulgar suas ações e o posicionamento pela gestão socioambiental contribui para agregação de valor a organização e a marca de seus produtos e serviços (Souza et al., 2009).

Neste contexto, o governo brasileiro tem se esforçado para fazer sua parte e adequar a legislação às novas demandas, exercendo assim a responsabilidade socioambiental através do seu poder de compra. Um exemplo foi a inclusão da variável sustentável no cadastro de itens no Catálogo de Materiais (CATMAT), disponível no Portal ComprasNet.

Porém, mesmo com a existência da legislação vigente e de manuais sobre licitações sustentáveis no Brasil, o que se observa é a baixa adesão a esta modalidade pelo setor público, conforme informações do Portal de Compras do Governo Federal - ComprasNet (2020).

Portanto, este estudo tem como objetivo central a construção e validação de uma cartilha como tecnologia educacional para a disseminação de conhecimento sobre a importância da compra de itens sustentáveis.

\section{Responsabilidade socioambiental}

O quadro socioambiental que caracteriza as sociedades contemporâneas revela que o impacto dos humanos sobre o meio ambiente tem tido consequências cada vez mais conturbadas, tanto em termos quantitativos quanto qualitativos (Jacobi, 2003).

Assim, a vertente da responsabilidade socioambiental contempla os aspectos sociais e ambientais ao se reportar a adoção de práticas com o intuito de explorar os deveres básicos dos cidadãos e também das empresas (Dias, 2006).

0 reconhecimento da importância das questões ambientais por parte das organizações, mesmo que não seja de caráter voluntário, já ocorre e é de extrema importância devido ao aumento da escassez de recursos naturais, que é fator de sobrevivência para as organizações e também para toda a sociedade (Pimentel e Marasea, 2004).

Ademais, as organizações que praticam a responsabilidade socioambiental tornam-se grandes influenciadoras, formadoras de opiniões de um número expressivo de pessoas, o que gera o marketing positivo para a instituição, ocasiona pressões políticas nas instâncias legislativas e executivas de cooperação com as empresas (Barbieri, 2011).

Apesar de muitas informações serem apresentadas para a sociedade através de matérias jornalísticas e publicitárias promovidas tanto pelo governo quanto por organizações não governamentais, a conscientização da população em geral ainda ocorre de forma lenta, de forma superficial e consideravelmente há pouco tempo. 0 que de fato que contribui para reverter este quadro, é a exposição dos desastres ambientais que trazem o assunto à mídia com maior frequência (Zozzoli, 2008).

Porter e Kramer (2006) chamam a atenção para o fato de que muitas companhias somente mudaram de comportamento a partir de cobranças públicas de sua responsabilidade, uma vez que estas cobranças são relativamente recentes e anteriormente não havia este tipo de cobrança no ramo empresarial. 


\section{Processo de compra de itens sustentáveis}

No desenvolvimento do processo de compras de itens sustentáveis por parte das organizações, busca-se agregar valor às marcas a partir da incorporação da preocupação com as questões ambientais.

Com relação ao processo de compras públicas, o incentivo e apoio à licitação sustentável vêm aumentando gradativamente, o que significa que além dos critérios tradicionais das compras públicas, como primar pelo menor preço, fatores socioambientais estão sendo incorporados a este processo. Isso possibilita fomentar grupos que se diferenciam por critérios ambientais em seu processo produtivo (Oliveira e Santos, 2015).

Almejando incorporar critérios de eficiência econômica, social e ambiental de forma simultânea, o conceito de compras sustentáveis também busca entendimento da realidade ampliando seus contornos, o que gera resultados superiores aos da política pública tradicional, pois visa médio e longo prazo (Oliveira e Santos, 2015).

A decisão de comprar sustentável é muito importante e os recursos públicos incorridos neste processo podem gerar impactos significativos, o que sugere reflexão do agente tomador de decisão (Biderman et al., 2006).

A prática da licitação sustentável tem se disseminado rapidamente em todo o mundo e também no Brasil já existem ações por parte do governo. Porém, nas licitações públicas ainda acontecem debates sobre a legalidade da opção mais sustentável em termos socioambientais (Biderman et al., 2006).

\section{Legislação}

A defesa ao meio ambiente passou a ser considerada como um princípio a ser observado para atividades econômicas pela Constituição Federal de 1988, que incorporou o conceito de desenvolvimento sustentável em seu Capítulo VI, que constitui o Título VIII, dedicado à ordem social (Brasil, 1988).

A Constituição estabeleceu que todos têm direito ao meio ambiente ecologicamente equilibrado bem de uso comum do povo e essencial a sadia qualidade de vida, assim como o poder público tem o dever de defendê-lo e preservá-lo tanto para as gerações presentes quanto para as futuras, portanto, trata-se de uma Constituição socioambiental que possui um capítulo específico sobre o meio ambiente e também amplia os mecanismos para a defesa da natureza, conferindo a qualquer cidadão o direito de propor ação popular para proteger o meio ambiente, o patrimônio histórico e cultural e amplia a autonomia do Ministério Público quanto às questões socioambientais (Barbieri, 2011).

Conforme os conceitos de desenvolvimento sustentável foram evoluindo, os critérios de incorporação das perspectivas sociais, econômicas e ambientais foram se tornando necessários e assim o aprimoramento da legislação com a finalidade de normatizar o incentivo às ações sustentáveis.

Neste sentido, as normas sobre licitações sustentáveis descritas na Lei no 8.666/1993 (Brasil, 1993), ganharam nova redação e foram atualizadas por outras, como a Lei no 8.883/1994 (Brasil, 1994), a Lei no 9.032/1995 (Brasil, 1995), a Lei no 9.648/1998 (Brasil, 1998), a Lei no 10.520/2002 (Brasil, 2002) e a Lei no 12.349/2010 (Brasil, 2010). A Lei no 12.349/2010 (Brasil, 2010), que dá nova redação ao art. 3o da Lei no 8.666/1993 (Brasil, 1003), inclui o desenvolvimento nacional sustentável em seu texto:

Art, 3ํ A licitação destina-se a garantir a observância do princípio constitucional da isonomia, a seleção da proposta mais vantajosa para a administração e a promoção do desenvolvimento nacional sustentável e será processada e julgada em estrita conformidade com os princípios básicos da legalidade, da impessoalidade, da moralidade, da igualdade, da publicidade, da probidade 
administrativa, da vinculação ao instrumento convocatório, do julgamento objetivo e dos que lhes são correlatos (Brasil, 2010).

A Lei no 11.079/2004 (Brasil, 2004) institui normas gerais para licitação e contratação de parceria público-privada no âmbito da administração pública, porém Biderman et al. (2006, p. 37) ressaltam que esta legislação deve ser interpretada "de forma coerente com o restante das normas do ordenamento jurídico nacional, em particular, com os preceitos da Lei de Política Nacional do Meio Ambiente (Lei no 6.938/1981), que orienta o Estado na gestão pública dos interesses ambientais".

A Lei no 6.938/1981 (Brasil, 1981) em seu texto evidencia a necessidade de tornar desenvolvimento econômico-social compatível com a preservação da qualidade do meio ambiente, através de critérios e padrões bem definidos e pré-estabelecidos. Portanto, as licitações públicas deveriam respeitar tais recomendações (Biderman et al., 2006).

\section{Resistência dos agentes públicos}

De acordo com o Ministério do Planejamento, Orçamento e Gestão os gastos públicos podem oscilar entre $15 \%$ e $30 \%$ do PIB de um país (MPOG, 2012). Assim, é razoável pensar o Estado como um grande impulsionador da economia e não somente um instrumento das necessidades administrativas (Justen Filho, 2011).

As compras públicas podem fomentar o mercado sustentável, pois um maior número de compradores optando por produtos sustentáveis fará com que ocorra uma oferta maior estimulada por esta demanda, desencadeando preços mais competitivos e aumentando a margem de lucro dos pequenos produtores, podendo se tornar incentivo para a indústria através da recompensa pelo melhor desempenho ambiental de seus produtos (Biderman et al., 2006).

Porém, apesar de haver legislação vigente sobre o assunto, muitos fatores limitam e impedem a realização das compras sustentáveis na esfera pública. Fatores individuais de natureza cognitiva e afetiva, por exemplo, ou fatores organizacionais, de controle gerencial, de estrutura organizacional e também de cultura organizacional podem ser considerados fatores limitantes (Preuss e Walker, 2011).

Biderman et al. (2006, p. 42) afirmam que "o argumento normalmente mais usado contra a licitação sustentável é que os produtos sustentáveis custam mais". Os autores também enfatizam que a falta de informação e de experiência do consumidor dificultam a comparação das características de um produto específico, tornando-se uma das barreiras mais comuns para a implementação da licitação de produtos sustentáveis (Biderman et al., 2006).

A falta de engajamento dos servidores, juntamente com o pretexto de possíveis impedimentos legais para o enfoque socioambiental nas licitações também constitui um fator de impedimento bastante comum (Betiol et al., 2012).

Outros obstáculos são a falta de conhecimento, de vontade política e de incentivo para estimular a mudança de comportamento necessária para implementar as compras públicas de itens sustentáveis (Santos et al., 2010).

Esta realidade também pode ser observada no Instituto Federal de Educação, Ciência e Tecnologia do Rio de Janeiro que desde sua criação vem realizando um número pouco expressivo de compras de itens sustentáveis, contudo, a situação se agravou nos últimos anos em virtude da restrição de verbas e somente quatro unidades realizaram compras de itens sustentáveis nos últimos dois anos conforme informações do Portal de compras do Governo Federal - ComprasNet (2020).

Buscando apurar os fatores impeditivos da compra de itens sustentáveis no Instituto Federal de Educação, Ciência e Tecnologia do Rio de Janeiro, fez-se necessária a primeira fase da pesquisa para realizar um diagnóstico situacional junto aos servidores.

Rev. Bras. Gest. Amb. Sustent., 2020, vol. 7, n. 17, p. 1619-1636. 


\section{Tecnologia educacional}

0 desenvolvimento de práticas educativas é fundamental para alcançar o caminho para uma sociedade mais sustentável, que promova atitudes reflexivas a respeito das questões ambientais, formando novas mentalidades, conhecimentos e comportamentos. (Jacobi e Grandisoli, 2017).

O conceito de tecnologia educacional foi publicado pela Comissão de Tecnologia Instrucional da AECT em 1970 e compreende a maneira sistemática de planejar, desenvolver e avaliar o processo total do ensino-aprendizagem em termos de objetivos específicos, baseada em pesquisa sobre aprendizagem humana e comunicação e emprega uma combinação de recursos humanos a fim de realizar instrução mais efetiva e reflexiva. (Sancho, 1997).

A criação de ambientes de aprendizagem deve abarcar a pesquisa para a resolução de problemas e facilitar o processo de informações, pois o compartilhamento de conhecimento facilita o processo reconstrutivo (Batistella, 1999).

Utilizando a tecnologia educacional no formato de cartilha, buscou-se o detalhamento necessário para auxiliar os servidores no entendimento da legislação e na conscientizar sobre a importância do tema.

\section{Material e métodos}

A pesquisa compreendeu um estudo de desenvolvimento metodológico, pois trata de investigar, organizar e analisar dados com a finalidade de construir, validar e avaliar um instrumento específico para posterior utilização, em formato de cartilha educativa (Polit e Beck, 2011).

Este estudo foi realizado em três fases distintas e utilizou as abordagens qualitativa e quantitativa, ou abordagem de métodos mistos. A pesquisa de métodos mistos abarca o uso das duas abordagens de forma conjunta, ou seja, associa as duas abordagens de modo a construir um melhor resultado (Creswell, 2010).

\section{Primeira fase - Revisão Integrativa e diagnóstico situacional}

Na primeira fase deste estudo, foi realizada uma revisão bibliográfica sistemática que empregou a Revisão Integrativa a partir da pergunta norteadora da pesquisa: "Quais são as dificuldades encontradas na realização da compra de itens sustentáveis na administração pública?" e seguiu etapas bem definidas e de forma sucessiva (Botelho et al., 2011).

O material para a revisão bibliográfica foi selecionado a partir de trabalhos que abordam a temática e a legislação vigente, disponíveis na internet e filtrados a partir da ferramenta Google Scholar. Buscou-se a contextualização em ordem cronológica do tema para acompanhar a evolução dos conceitos até a atualidade. Assim, excluíram-se trabalhos disponibilizados de forma incompleta.

A seguir, foi realizada uma pesquisa exploratória com abordagem qualitativa e uso do questionário como técnica de coleta de dados junto aos servidores do Instituto Federal de Educação, Ciência e Tecnologia do Rio de Janeiro, com a finalidade de realizar um diagnóstico situacional sobre as dificuldades apresentadas na realização da compra de itens sustentáveis.

A pesquisa exploratória permite ao pesquisador uma visão mais ampla de um fato pouco explorado, possibilitando o esclarecimento, desenvolvimento e aprofundamento da pesquisa a partir dos dados levantados (Gil, 2008). E o uso da abordagem qualitativa possibilita ao pesquisador uma avaliação da compreensão de indivíduos sobre um determinado problema social ou humano (Creswell, 2010).

Os sujeitos deste estudo compreendem os servidores do Instituto Federal de Educação, Ciência e Tecnologia do Rio de Janeiro responsáveis pela solicitação de compra 
de itens. Embora os responsáveis pelos setores sejam oficialmente os solicitantes de compras dos campi e da Reitoria, todos os servidores podem solicitar a compra de um item ao seu chefe imediato, porém somente o coordenador ou diretor poderá encaminhar esta solicitação ao setor competente.

Neste contexto, os servidores foram selecionados de forma intencional, pois a amostragem intencional auxilia melhor o pesquisador no entendimento do problema em questão (Creswell, 2010).

Os critérios para participação foram a livre concordância na participação da pesquisa e o participante ter realizado alguma solicitação de compras de itens nos últimos doze meses na instituição em decorrência do cargo ocupado.

A coleta de dados foi realizada através do questionário de respostas abertas, construído com quatro questões elaboradas numa linguagem simples e direta com a finalidade de fornecer subsídios para a construção da cartilha a partir das dificuldades apresentadas pelos servidores do Instituto Federal de Educação, Ciência e Tecnologia do Rio de Janeiro na realização da licitação sustentável.

Com o auxílio da ferramenta Survey Monkey, o questionário foi enviado via e-mail para 48 servidores durante o mês de julho de 2019. Este total de servidores deu-se a partir de três servidores de cada um dos quinze campi do Instituto Federal de Educação, Ciência e Tecnologia do Rio de Janeiro e três servidores da Reitoria que estavam aptos a participação pelos critérios de seleção.

As questões apresentadas aos participantes foram: 1 - Você tem algum conhecimento sobre a legislação de licitação sustentável? 2 - Você costuma solicitar a compra de que tipos de materiais? 3 - Você busca por itens sustentáveis ao realizar uma solicitação de compra? Por que? 4 - Que dificuldades você identifica na execução da compra de itens sustentáveis?

\section{Segunda fase - Elaboração da cartilha}

A elaboração da cartilha envolveu as etapas de escolha dos assuntos abordados, a elaboração do conteúdo da cartilha, com a construção de textos e ilustrações, e a edição gráfica.

Segundo Brighenti et al. (2015), no que tange o início da elaboração, fazer com que o público alvo se identifique com as questões apresentadas e nas ações retratadas de forma a compreender a extensão do impacto de suas atitudes, melhora a compreensão e a efetividade do material.

Assim, a seleção de conteúdo buscou sanar as dúvidas levantadas pelos servidores na pesquisa da primeira fase do estudo, de acordo com as evidências encontradas na literatura e a determinação da legislação vigente.

Após realizada a seleção dos conteúdos, buscou-se o uso de uma linguagem informal sem interlocução de personagens, ou seja, de forma direta e clara, somada às ilustrações para não tornar a leitura cansativa e garantir sua fácil compreensão.

Para a construção das ilustrações e da diagramação na fase de edição gráfica da cartilha, o processo de desenvolvimento contou com o auxílio de um designer gráfico contratado, a fim de garantir maior profissionalismo, aparência atrativa e melhor acabamento da cartilha.

\section{Terceira fase - Validação da cartilha}

A terceira fase da pesquisa compreendeu a validação da linguagem, do conteúdo e da aparência da cartilha preliminar pelos juízes especialistas para a realização de adequações e posteriormente, pelo público alvo, a adequação e a revisão da cartilha preliminar para a versão final.

A validação do conteúdo e da aparência da cartilha junto aos juízes especialistas e posteriormente pelo público alvo faz-se necessária para garantir credibilidade e 
confiabilidade ao material, minimizando a possibilidade de erros e atestando sua qualidade (Lobiondo-Wood e Haber, 2001).

Para garantir a precisão pretendida com o processo de validação da cartilha, foi utilizada a abordagem quantitativa através do uso da Escala Likert (1932) em todas as suas etapas, com vistas a maior efetividade na verificação do grau de confiabilidade da cartilha como ferramenta apropriada para disseminação de conhecimento sobre a compra de itens sustentáveis. As pesquisas quantitativas buscam a magnitude e as causas dos fenômenos sociais, desprezando a dimensão subjetiva e utilizam procedimentos controlados, centrados na objetividade (Cunha, 2014).

Tabela 1. Critérios para seleção dos juízes.

\begin{tabular}{|c|c|}
\hline Juízes & Critérios de seleção \\
\hline Docentes & $\begin{array}{l}\text { - Concordar em participar da pesquisa } \\
\text { - Ter titulação de mestre e ou doutor } \\
\text { - Ter desenvolvido trabalho científico na área educacional publicado nos } \\
\text { últimos cinco anos }\end{array}$ \\
\hline $\begin{array}{l}\text { Profissionais } \\
\text { técnicos }\end{array}$ & $\begin{array}{l}\text { - Concordar em participar da pesquisa } \\
\text { - Ter graduação } \\
\text { - Atuar no setor de compras } \\
\text { - Ter experiência mínima de } 3 \text { anos na área de licitação sustentável }\end{array}$ \\
\hline Designers gráficos & $\begin{array}{l}\text { - Concordar em participar da pesquisa } \\
\text { - Ter graduação } \\
\text { - Atuar no setor de comunicação } \\
\text { - Ter experiência profissional na construção de material educativo nos } \\
\text { últimos cinco anos }\end{array}$ \\
\hline
\end{tabular}

Com relação à validação pelos juízes especialistas, foi observada a sugestão de Pasquali (1997), que recomenda um número entre seis a vinte especialistas. Assim, foram convidados quinze juízes especialistas para participar da pesquisa, divididos em três grupos de cinco juízes, com a finalidade de validar a linguagem, o conteúdo e a aparência da cartilha.

Aos juízes docentes coube a avaliação da linguagem utilizada na cartilha enquanto material educativo. Os juízes profissionais técnicos validaram o conteúdo da cartilha de acordo com a legislação vigente. Os juízes designers gráficos ficaram responsáveis pela validação da aparência da cartilha.

Todos os juízes foram selecionados a partir do quadro de servidores ativos do Instituto Federal de Educação, Ciência e Tecnologia do Rio de Janeiro, através de análise do Currículo Lattes. Desta forma, para fins de seleção, foram convidados os cinco docentes, os cinco profissionais técnicos e os cinco designers gráficos com maior tempo de experiência em suas respectivas áreas.

Foi encaminhado para cada um dos juízes, via e-mail, o questionário de validação juntamente com o convite formal para participação na pesquisa, cópia da cartilha e o Termo de consentimento livre e esclarecido (TCLE).

Considerando a Lei no 13.979/2020 (Brasil, 2020) e o Decreto no 46.966/2020 (Rio de Janeiro, 2020), que estipulam cumprimento de quarentena em consequência da pandemia de COVID19, o contato com os juízes aconteceu via e-mail durante o mês de abril de 2020 .

O questionário foi desenvolvido com questões fechadas e respostas de acordo com a Escala Likert (1932), onde o participante pode optar por responder: 1 Totalmente 
adequado, 2 Adequado, 3 Parcialmente adequado, 4 Inadequado. Ao final do questionário, foi disponibilizado um espaço para sugestões e observações para que o juiz pudesse justificar suas escolhas ou expor suas impressões sobre o material.

Foi utilizado o Índice de Validade de Conteúdo (IVC), para medir a concordância dos juízes no que tange a representatividade de cada item com relação ao conteúdo apresentado no estudo (Rubio et al., 2003).

Embora não exista um consenso na literatura sobre a avaliação do método como um todo, sua fórmula para cálculo geralmente utilizada pelos autores da área é a seguinte:

$$
\text { IVC }=\frac{\text { Número de respostas "1" ou "2" }}{\text { Número total de respostas }}
$$

Ainda de acordo com a sugestão de Pasquali (1997), deve haver a concordância de ao menos $80 \%$ dos juízes sobre a adequação de cada item para que este seja considerado válido.

Assim, para que o item seja validado deve haver concordância dos juízes no somatório das respostas " 1 " e "2". No caso de concordância de respostas " 3 ", o item é revisado, e no caso de concordância de resposta "4", o item é descartado. Ressalta-se que em caso de respostas " 3 " ou "4", foi solicitado aos juízes que fizessem um apontamento justificando a resposta, com a finalidade de adequar o item.

Após o processo de validação pelos juízes especialistas, a cartilha foi revisada de acordo com os resultados apurados, e foi encaminhada para a validação junto ao público alvo.

O questionário de validação juntamente com o convite formal para participação na pesquisa e o Termo de consentimento livre e esclarecido (TCLE), foram enviados a um servidor de cada campus e da Reitoria, via e-mail, no total de dezesseis participantes na categoria de público alvo.

A escolha destes representantes deu-se de forma aleatória, a partir dos contatos de e-mail divulgados no portal institucional, onde se buscou prioritariamente os setores que necessariamente realizam compras como, por exemplo, prefeituras, direções, setores de almoxarifado, coordenações de extensão, setores de laboratório, setores de informática.

Foram enviados dois e-mails para setores diferentes do mesmo campus e, para fins da pesquisa, foi considerado o primeiro a retornar com o formulário de validação preenchido e que além da concordância em participar da pesquisa, o servidor tenha informado ter sido responsável pela solicitação de ao menos uma compra no ano de 2019 em seu campus.

Após o processo de validação pelo público alvo, a cartilha foi novamente ajustada e revisada para posterior distribuição através de meios eletrônicos.

\section{Limitação do método}

Pode-se considerar como limitante do método o diagnóstico situacional ser realizado somente no âmbito do Instituto Federal de Educação, Ciência e Tecnologia do Rio de Janeiro, não considerando outras realidades em outros órgãos públicos para nortear a pesquisa.

Também pode se considerar como limitante do método a escassez de trabalhos publicados que versam sobre a construção de tecnologia educacional em outras áreas de conhecimento além da área de saúde. 


\section{Resultados e discussão}

A pesquisa apresentou resultados distintos em cada uma de suas fases, sendo estes: o diagnóstico situacional realizado junto aos servidores na primeira fase, a construção da cartilha baseada na legislação e no diagnóstico situacional na segunda fase e o processo de validação da cartilha na terceira fase, que abarcou a validação de conteúdo, de linguagem, de aparência e a validação pelo público alvo.

\section{Aspectos constitutivos da cartilha}

Na primeira fase da pesquisa, foi realizado o diagnostico situacional através do questionário aplicado aos servidores dos setores que mais executam compras de cada campus, o que possibilitou dimensionar as principais dúvidas dos servidores com relação à compra de itens sustentáveis.

O questionário foi enviado por e-mail para 48 servidores responsáveis pela solicitação de compras dos seus respectivos setores e foi aplicado por e-mail através da ferramenta Survey Monkey.

O questionário ficou disponível para resposta dos servidores pelo período de um mês e, embora muitos servidores tenham retornado ao e-mail justificando a negativa em participar da pesquisa devido ao momento político que o país atravessa e o consequente receio de sofrerem retaliação por ocuparem cargo de gestão, a taxa de retorno foi de $31,25 \%$.

Nesta fase da pesquisa foi possível apurar que $100 \%$ dos servidores participantes declararam não ter algum conhecimento sobre a legislação sustentável e também $100 \%$ alegaram não buscar por itens sustentáveis no ato da solicitação de compra.

Sobre os itens que costumam ser solicitados para a realização da compra, 33,33\% dos servidores participantes declarou solicitar material de escritório, 33,33\% a compra de componentes eletrônicos e os outros 33,33\% instrumentos de medição para laboratórios.

Com relação ao desinteresse por buscar itens sustentáveis na solicitação da compra, os motivos alegados foram a burocracia, a compra sustentável não se aplicar ao setor e o servidor nunca ter prestado atenção a esta questão, cada item foi citado por $33,33 \%$ dos servidores.

No que diz respeito às dificuldades identificadas na execução da compra de itens sustentáveis, 33,33\% identifica a burocracia na compra de itens sustentáveis, 33,33\% alega que desconhece o assunto e outros $33,33 \%$ destacou que o preço é o principal empecilho.

Tabela 2. Elaboração do conteúdo da cartilha.

\begin{tabular}{|l|l|}
\hline $\begin{array}{l}\text { Questões apresentadas pelos servidores } \\
\text { participantes }\end{array}$ & \multicolumn{1}{c|}{ Conteúdo desenvolvido } \\
\hline Desconhecimento do assunto & $\begin{array}{l}\text { - O que é responsabilidade socioambiental. } \\
\text { - O que é item sustentável. } \\
\text { - Abordagem da legislação. }\end{array}$ \\
\hline Preço & - Exemplo prático de comparação de preços. \\
\hline Burocracia & $\begin{array}{l}\text { - Descrição das etapas para a realização da compra } \\
\text { de item sustentável. } \\
\text { - Amparo legal. }\end{array}$ \\
\hline
\end{tabular}


Assim, na segunda fase da pesquisa, a elaboração da cartilha buscou sanar as dúvidas sobre as questões levantadas pelos servidores. Desta forma, o conteúdo ficou dividido em Responsabilidade socioambiental: o que é, sua importância e como contribuir para sua promoção? e Item sustentável: o que é, como realizar sua compra e quais são seus benefícios?

Realizada a versão preliminar da cartilha, a mesma foi encaminhada para os juízes para o processo de validação de linguagem, conteúdo e aparência.

$\mathrm{Na}$ apuração dos resultados demonstrados nas tabelas a seguir, para melhor compreensão, utilizou-se as legendas TA para Totalmente adequado, A para Adequado, PA para Parcialmente adequado, e I para Inadequado, conforme o formulário de validação enviado aos juízes. Em seguida, as tabelas apresentam o número de juízes que consideraram as referidas opções e na última coluna o cálculo do Índice de Validade de Conteúdo (IVC).

\section{Validação da linguagem}

O grupo de juízes que validaram a linguagem utilizada na cartilha foi formado por três mulheres e dois homens, com formação em história, pedagogia e língua portuguesa e literatura, sendo dois participantes com titulação de mestrado e três de doutorado.

A seguir, estão apresentados os resultados apurados de acordo com o entendimento dos juízes de validação da linguagem.

Tabela 3. Validação da linguagem.

\begin{tabular}{|l|c|c|c|c|c|}
\hline Clareza da linguagem & TA & A & PA & I & IVC \\
\hline As informações estão apresentadas de forma clara e objetivas & 4 & - & 1 & - & $80 \%$ \\
\hline As informações estão organizadas em concordância e ortografia & 2 & 2 & 1 & - & $80 \%$ \\
\hline As informações da capa estão coerentes & 4 & 1 & & - & $100 \%$ \\
\hline O tamanho do título e dos tópicos estão adequado & 1 & 2 & 2 & - & $60 \%$ \\
\hline O número de páginas está apropriado & 4 & 1 & - & - & $100 \%$ \\
\hline Compreensão & TA & A & PA & I & IVC \\
\hline A redação está adequada ao nível do público alvo (servidor público) & 5 & & - & - & $100 \%$ \\
\hline As informações estão organizadas numa sequencia lógica & 4 & 1 & - & - & $100 \%$ \\
\hline A redação é de fácil compreensão & 3 & 2 & - & - & $100 \%$ \\
\hline A linguagem é explicativa & 4 & 1 & - & - & $100 \%$ \\
\hline
\end{tabular}

Legenda: TA, Totalmente adequado; A, Adequado; PA, Parcialmente adequado; I, Inadequado; IVC, Índice de Validade de Conteúdo.

Com relação à clareza da linguagem, houve concordância sobre as informações estarem apresentadas de forma clara e objetivas, também sobre as informações da capa estarem coerentes e sobre o número de páginas estar apropriado. Portanto estes itens foram considerados válidos e não sofreram alterações além de pequenos ajustes de concordância.

Para validar o tamanho do título e dos tópicos de forma adequada, foram inseridos os subtítulos “5.1 Selos ambientais" e "6.1 Exemplo prático", conforme sugestão dos juízes, sob a justificativa que essas mudanças "facilitam a leitura, direcionam o leitor e tornam a leitura mais leve" (JD2). Com a mesma justificativa e finalidade, no subtítulo "7. Quais são os benefícios de comprar tens sustentáveis", na página 11, o texto foi subdivido em tópicos. 
Quanto à compreensão, os juízes concordaram na validação dos itens de todos os itens, portanto não foi necessário fazer ajustes.

\section{Validação do conteúdo}

A seguir, estão apresentados os resultados apurados para cada dos itens examinados na validação do conteúdo, de acordo com o entendimento dos juízes técnicos.

Tabela 4. Validação do conteúdo.

\begin{tabular}{|c|c|c|c|c|c|}
\hline Pertinência prática & TA & A & PA & I & IVC \\
\hline As informações apresentadas estão legalmente corretas & 3 & 2 & - & - & $100 \%$ \\
\hline A cartilha propõe a construção de conhecimento & 3 & 2 & - & - & $100 \%$ \\
\hline Relevância teórica & TA & A & PA & I & IVC \\
\hline O material aborda aspectos relevantes & 3 & 2 & - & - & $100 \%$ \\
\hline O material permite aprendizado sobre o assunto & 5 & & - & - & $100 \%$ \\
\hline $\begin{array}{l}\text { O material está adequado para ser usado por qualquer } \\
\text { servidor }\end{array}$ & 3 & 2 & - & - & $100 \%$ \\
\hline Objetivos & TA & A & PA & I & IVC \\
\hline $\begin{array}{l}\text { O conteúdo está adequado para a promoção da gestão } \\
\text { socioambientalmente responsável de compras }\end{array}$ & 3 & 1 & 1 & - & $80 \%$ \\
\hline $\begin{array}{l}\text { As informações estão coerentes com o objetivo de promoção } \\
\text { da gestão socioambientalmente responsável de compras }\end{array}$ & 4 & 1 & - & - & $100 \%$ \\
\hline $\begin{array}{l}0 \text { material aborda os assuntos necessários para a } \\
\text { compreensão do objetivo }\end{array}$ & 3 & 1 & - & - & $100 \%$ \\
\hline
\end{tabular}

Legenda: TA, Totalmente adequado; A, Adequado; PA, Parcialmente adequado; I, Inadequado; IVC, Índice de Validade de Conteúdo.

O grupo de juízes que validaram o conteúdo foi composto por duas mulheres e três homens, com formação nas áreas de administração, direito, matemática e ecologia de ecossistemas.

Outros dados importantes e que contribuem para melhor avaliação da cartilha é que os juízes são provenientes de quatro áreas de formação diferentes, que compreendem administração, direito, matemática e ecologia de ecossistemas, e que possuem uma média de 8,4 anos de exercício profissional no referido setor.

Quanto ao conteúdo da cartilha, tanto na pertinência prática, quanto na relevância teórica e nos objetivos, houve concordância na validação pelos juízes. Portanto, nenhum item precisou ser readequado.

Porém, foi observada a sugestão de um dos juízes que enfatizou que a pesquisa de preço deve compreender os últimos 180 dias para "ter uma pesquisa com mais chances de demonstrar o real valor de mercado do item" (JPT02), conforme disposto na Instrução Normativa no 03 de 2017. Tal sugestão foi inserida na página 11 da cartilha.

Foi sugerido por um dos juízes uma abordagem maior às normativas que possibilitam a aquisição de produtos ou serviços sustentáveis, porém essa sugestão foi descartada visto que uma cartilha de cunho demasiadamente técnico fugiria da proposta original que é a de aproximar a linguagem do material educativo à do servidor. 


\section{Validação da aparência}

O grupo de juízes que validaram a aparência foi composto por quatro mulheres e um homem, com formação nas áreas de publicidade, jornalismo e relações públicas, tendo um juiz graduação, três juízes mestrado e um juiz doutorado.

A seguir, estão apresentados os resultados apurados de acordo com o entendimento dos juízes designers gráficos na validação da aparência.

Tabela 5. Validação da aparência.

\begin{tabular}{|l|c|c|c|c|c|}
\hline Estrutura e apresentação & TA & A & PA & I & IVC \\
\hline As cores e o layout facilitam a leitura & 1 & 2 & 2 & - & $60 \%$ \\
\hline As ilustrações estão bastante expressivas & - & 5 & - & - & $100 \%$ \\
\hline As ilustrações estão condizentes com o conteúdo & - & 4 & - & 1 & $80 \%$ \\
\hline As ilustrações estão em quantidade suficiente & 2 & 2 & - & 1 & $80 \%$ \\
\hline O material está apropriado para o formato de cartilha & 1 & 1 & 2 & 1 & $40 \%$ \\
\hline O tamanho da fonte e o tipo de letra favorecem a leitura & 1 & 2 & 1 & 1 & $60 \%$ \\
\hline O propósito está evidente & - & 4 & - & 1 & $80 \%$ \\
\hline
\end{tabular}

Legenda: TA, Totalmente adequado; A, Adequado; PA, Parcialmente adequado; I, Inadequado; IVC, Índice de Validade de Conteúdo.

De acordo com os critérios de seleção, todos os designers selecionados que concordaram em participar do estudo possuem o nível mínimo de formação em graduação e possuem uma média de 12,4 anos de exercício profissional.

Na estrutura e apresentação da cartilha, houve concordância na validação dos itens referentes às ilustrações nos quesitos expressividade, condizente com o conteúdo e quantidade suficiente. Também houve concordância na validação do item sobre o propósito da cartilha estar evidente.

Como nenhum dos itens restantes obteve percentual de inadequação superior a $80 \%$, nenhum item foi descartado. Assim, os itens não validados foram reajustados seguindo as sugestões e recomendações dos juízes.

0 item sobre as cores e layout facilitarem a leitura foi alterado de acordo com a observação de três juízes que sugeriram a retirada das figuras ao fundo dos textos, pois "acabam cansando a leitura e dificultando o entendimento" (JDG03).

Assim, a figura da página 3 foi recolocada em tamanho menor e sem transparência no canto direito da página e a figura da página 13 foi descartada por conter um texto longo e não haver espaço na página para realocação.

No item para validar se o material está apropriado para o formato da cartilha, foram consideradas pelos juízes as mesmas justificativas da questão anterior, ou seja, que as figuras no fundo do texto prejudicam o formato da cartilha.

Foi também sugerido por um dos juízes que fosse utilizado menos fotografias e mais figuras no formato de desenho para que as imagens possam "privilegiar o poder de transformação que o processo de sustentabilidade traz para a sociedade" (JDG01). Desta forma, as fotografias das páginas 4, 6 e 11 foram trocadas por desenhos mais lúdicos e mais educativos.

Sobre o item tamanho da fonte e tipo de letra favorecerem a leitura, um dos juízes sugeriu usar tamanhos de fontes diferentes, pois "de acordo com o conteúdo podem proporcionar uma leitura melhor" (JDG05), enquanto que outros dois juízes recomendaram padronizar o tamanho das fontes para manter a formalidade do documento. Optou-se por seguir a recomendação da maioria. 
Outra sugestão proposta por dois dos juízes foi o aumento da fonte no título da cartilha para maior destaque. A fonte do título que originalmente tinha o tamanho 40 foi alterada para o tamanho 54 .

\section{Validação pelo público alvo}

Após o processo de validação da cartilha pelos juízes especialistas, foram realizados os ajustes necessários para sua adequação e a cartilha foi novamente revisada em todos os seus detalhes.

A seguir, a cartilha foi encaminhada, via e-mail, para servidores de todos os campi com a finalidade de validá-la junto ao público alvo.

Os servidores foram escolhidos de forma aleatória e foram formalmente convidados a participarem da pesquisa após a confirmação de terem realizado pelo menos uma solicitação de compra de itens no ano de 2019.

$\mathrm{Na}$ Tabela 6, estão os resultados apurados de acordo com o entendimento do público alvo.

Tabela 6. Validação pelo público alvo.

\begin{tabular}{|l|c|c|c|c|c|}
\hline Organização & TA & A & PA & I & IVC \\
\hline A quantidade de informação por página está adequada & 15 & 1 & - & - & $100 \%$ \\
\hline As informaç̃̃es estão apresentadas de forma organizada & 14 & 2 & - & - & $100 \%$ \\
\hline Escrita e conteúdo & TA & A & PA & I & IVC \\
\hline $\begin{array}{l}\text { Ficou claro que se trata de uma cartilha educacional para } \\
\text { promoção da responsabilidade socioambiental de compras }\end{array}$ & 15 & - & 1 & - & $93,75 \%$ \\
\hline A forma de escrita é de fácil compreensão & 16 & - & - & - & $100 \%$ \\
\hline A linguagem está adequada & 16 & - & - & - & $100 \%$ \\
\hline O conteúdo da cartilha é adequado & 13 & 3 & - & - & $100 \%$ \\
\hline A leitura é agradável & 15 & 1 & - & - & $100 \%$ \\
\hline Aparência & TA & A & PA & I & IVC \\
\hline A capa chama atenção para a leitura & 15 & - & 1 & - & $93,75 \%$ \\
\hline O texto está apresentado de forma bem distribuída & 14 & 2 & - & - & $100 \%$ \\
\hline O tamanho da letra está adequado & 16 & - & - & - & $100 \%$ \\
\hline O número de paginas está adequado & 14 & 2 & - & - & $100 \%$ \\
\hline As figuras facilitam a compreensão do texto & 15 & - & - & 1 & $93,75 \%$ \\
\hline Impressões & TA & A & PA & I & IVC \\
\hline $\begin{array}{l}\text { As informações motivam uma mudança de comportamento } \\
\text { nas solicitações de compra }\end{array}$ & 13 & 3 & - & - & $100 \%$ \\
\hline $\begin{array}{l}\text { A cartilha esclarece dúvidas sobre compra } \\
\text { socioambientalmente responsável }\end{array}$ & 16 & - & - & - & $100 \%$ \\
\hline A cartilha está apropriada a todos os servidores & 14 & 2 & - & - & $100 \%$ \\
\hline
\end{tabular}

A caracterização dos participantes do público alvo foi composta de nove mulheres e sete homens com atuação nos setores de Direção de Ensino, Gabinete da Direção, Coordenação de Extensão, Coordenação técnico Pedagógica, Secretaria de Ensino Médio e Técnico, Prefeitura e Coordenação de Compras.

Os setores de trabalho dos participantes foram variados, o que contribui para melhor avaliação da cartilha e a média de tempo de exercício profissional é de 7,06 anos.

Todos os itens avaliados alcançaram o IVC superior a $80 \%$ e foram considerados válidos de acordo com o entendimento do público alvo. 
O retorno no campo "sugestões e observações" foi bastante utilizado pelos servidores para descrever suas impressões e reforçar "a importância deste conteúdo visto a escassez de materiais desse teor que já tive acesso no IFRJ" (PA04).

Quatro servidores sugeriram a inclusão da tela do Painel de Preços do Governo, para melhor compreensão dos filtros citados no conteúdo. Assim, a referida tela foi inserida com destaque para a coluna de filtros na página 10 da cartilha.

0 restante do layout e do conteúdo permaneceram sem alterações.

\section{Conclusão}

Após verificar na literatura os fatores de resistência dos agentes públicos para não realização da compra de itens sustentáveis e constatar que os motivos declarados pelos servidores que participaram da pesquisa permanecem os mesmos que os estudos de Biderman e outros autores apontam desde 2006 até os dias atuais, a cartilha mostrou-se necessária para disseminar conhecimento e desmistificar o assunto.

Através do diagnóstico situacional, realizado na primeira fase da pesquisa, foi possível elaborar o conteúdo da cartilha enfatizando o processo formal de solicitação de compras de itens sustentáveis de acordo com a legislação vigente, utilizando-se de uma linguagem simplificada para o melhor entendimento do servidor.

A cartilha "Vamos pensar no planeta? Um pequeno gesto pode fazer uma grande diferença!" passou por um processo de validação rigoroso e ao final deste processo foi considerada válida pelos juízes especialistas alcançando a média do IVC de 87,50\%.

Ao final da avaliação do público alvo, constatou-se que o material é bastante pertinente para dirimir dúvidas e chamar a atenção do servidor para o assunto.

Considera-se assim, que o estudo alcançou o seu objetivo de construir uma tecnologia educacional válida para promover a gestão socioambientalmente responsável de compras no Instituto Federal de Educação, Ciência e Tecnologia do Rio de Janeiro.

Ressalta-se que o processo de construção de tecnologias educacionais no formato de cartilha é bastante comum na área de saúde, porém não é usual na área administrativa. Desta forma, espera-se que este estudo seja capaz de demonstrar a importância do desenvolvimento deste formato de material educativo para outras diversas áreas da administração.

A tecnologia educacional no formato de cartilha tem como principal atrativo a simplificação da linguagem e o uso de figuras para aproximar o público alvo do conteúdo que se quer explicar.

Portanto, torna-se uma solução alternativa à linguagem cansativa de documentos formais e que nem sempre são de fácil compreensão para o público alvo, como a legislação e os manuais, por exemplo.

Por fim, espera-se que esta cartilha tenha o devido alcance a nível institucional e que possa servir para outras instituições públicas promoverem a gestão socioambientalmente responsável de compras.

\section{Conflito de interesses}

Os autores declaram não haver conflito de interesses.

\section{Referências}

Ashley, P. A. (Coord.). Ética e responsabilidade social nos negócios. São Paulo: Saraiva, 2003. 
Barbieri, J. C. Gestão ambiental empresarial: conceitos, modelos e instrumentos. 3. ed. São Paulo: Saraiva, 2011.

Batistella, C. Estratégias de ensino-aprendizagem e as mudanças no modelo de atenção à saúde. Rio de Janeiro: EPSJV-FIOCRUZ/FAPERJ, 1999. (Relatório final de pesquisa).

Betiol, L. S.; Uehara, T. H. K.; Appugliese, G. A.; Adeodato, S.; Ramos, L.; Monzoni Neto, M. P. Compra sustentável: a força do consumo público e empresarial para uma economia verde e inclusiva. São Paulo: Programa Gestão Pública e Cidadania, 2012.

Biderman, R.; Macedo, L. S. V.; Monzoni, M.; Mazon, R. (Orgs.). Guia de compras públicas sustentáveis: uso do poder de compra do governo para a promoção do desenvolvimento sustentável. Rio de Janeiro: FGV, 2006.

Botelho, L. L. R.; Cunha, C. C. A.; Macedo, M. 0 método da revisão integrativa nos estudos organizacionais. Gestão e Sociedade, v. 5, n. 11, p. 121-136, 2011. https://doi.org/ 10.21171/ges.v5i11.1220

Brasil. Constituição da República Federativa do Brasil de 1988. Disponível em: $<$ http://www.planalto.gov.br/ccivil_03/constituicao/constituicao.htm>. Acesso em: 01 abr. 2020.

Brasil. Lei no 6.938, de 31 de agosto de 1981. Dispõe sobre a Política Nacional do Meio Ambiente, seus fins e mecanismos de formulação e aplicação, e dá outras providências. Disponível em: <http://www.planalto.gov.br/ccivil_03/leis/16938.htm>. Acesso em: 05 abr. 2019.

Brasil. Lei no 8.666, de 21 de junho de 1993. Regulamenta o art. 37, inciso XXI, da Constituição Federal, institui normas para licitações e contratos da Administração Pública e dá outras providências. Disponível em: <http://www.planalto.gov.br/ccivil_03/leis/ 18666cons.htm>. Acesso em: 06 abr. 2019.

Brasil. Lei no 11.079, de 30 de dezembro de 2004. Institui normas gerais para licitação e contratação de parceria público-privada no âmbito da administração pública. Disponível em: <http://www.planalto.gov.br/ccivil_03/_ato2004-2006/2004/lei/l11079.htm>. Acesso em: 05 abr. 2019.

Brasil. Lei no 12.349, de 15 de dezembro de 2010. Altera as Leis nos 8.666 , de 21 de junho de 1993, 8.958, de 20 de dezembro de 1994, e 10.973, de 2 de dezembro de 2004; e revoga o $\S 1^{\text {o }}$ do art. $2^{\text {o }}$ da Lei $n^{\circ} 11.273$, de 6 de fevereiro de 2006. Disponível em: <http://www.planalto.gov.br/ccivil_03/_Ato2007-2010/2010/Lei/L12349.htm>. Acesso em: 05 abr. 2019.

Brasil. Lei no 13.979, de 06 de fevereiro de 2020. Dispõe sobre as medidas para enfrentamento da emergência de saúde pública de importância internacional decorrente do coronavírus responsável pelo surto de 2019. Disponível em: <http://www.planalto.gov.br/ccivil_03/_ato2019-2022/2020/lei/L13979.htm>. Acesso em: 01 abr. 2020.

Brighenti, J.; Biavatti, V. T.; Souza, T. R. Metodologias de ensino-aprendizagem: uma abordagem sob a percepção dos alunos. Revista GUAL, v. 8, n. 3, p. 281-304, 2015. Disponível em: <https://periodicos.ufsc.br/index.php/gual/article/view/19834535.2015v8n3p281>. Acesso em: 14 mar. 2019.

Creswell, J. W. W. Projeto de pesquisa: métodos qualitativo, quantitativo e misto. 3. ed. Porto Alegre: Artmed, 2010. 
Cunha, A. G. A. Infecções das vias aéreas superiores: construção e validação de tecnologia educacional com educadoras infantis. Manaus: Universidade Federal do Amazonas, 2014. (Dissertação de mestrado).

Dias, R. Gestão ambiental: responsabilidade social e sustentabilidade. São Paulo: Atlas, 2006.

Gil, A. C. Métodos e técnicas de pesquisa social. 6. ed. São Paulo: Atlas, 2008.

Jacobi, P. Educação Ambiental, cidadania e sustentabilidade. Cadernos de Pesquisa, n. 118, p. 189-205, 2003.

Jacobi, P. R.; Grandisoli, E. Água e sustentabilidade: desafios, perspectivas e soluções. São Paulo: IEE-USP e Reconectta, 2017.

Justen Filho, M. Desenvolvimento nacional sustentável: contratações administrativas e o regime introduzido pela Lei 12.349 . Informativo Justen, Pereira, Oliveira e Talamini, n. 50, 2011. Disponível em: <http://www.justen.com.br//informativo.php? \&informativo $=50$ \&artigo $=1077 \& \mathrm{l}=\mathrm{pt}>$. Acesso em: 09 jan. 2019.

Likert, R. A technique for the measurement of attitudes. Archives of Psychology, v. 140, p. 1-55, 1932. Disponível em: <https://legacy.voteview.com/pdf/Likert_1932.pdf>. Acesso em: 09 jan. 2019.

Lobiondo-Wood, G.; Haber, J. Pesquisa em enfermagem: métodos, avaliação crítica e utilização. 4. ed. Rio de Janeiro: Guanabara Koogan, 2001.

MPOG - Ministério do Planejamento, Orçamento e Gestão. Compras e inovação. Brasília: MPOG, 2012. Disponível em: <http://cpsustentaveis.planejamento.gov.br/compras-einovacao>. Acesso em: 15 dez. 2018.

Oliveira, B.C.S.C.M.; Santos, L. M. Compras públicas como política para o desenvolvimento sustentável. Revista de Administração Pública, v. 49, n. 1, p. 189-206, 2015. https://doi.org/10.1590/0034-76121833

Pasquali, L. Psicometria: teoria e aplicações. Brasília: UnB, 1997.

Penna, C. G. 0 estado do planeta: sociedade de consumo e degradação ambiental. Rio de Janeiro: Record, 1999.

Pimentel, R. C.; Marasea, D. C. C. Gestão empreendedora com responsabilidade social. Ribeirão Preto: Legis Summa, 2004.

Polit, D. F.; Beck, C. T. Fundamentos de pesquisa em enfermagem: avaliação de evidências para a prática da enfermagem. 7. ed. Porto Alegre: Artmed, 2011.

Portal Comprasnet. Portal de compras do Governo Federal. Disponível em: <http://www.comprasnet.gov.br/>. Acesso em: 18 jan. 2020.

Porter, M.; Kramer, M. Strategy and society: The link between competitive advantage and corporate social responsibility. Harvard Business Review, v. 4, n. 12, p. 78-92, 2006.

Preuss, L.; Walker, H. Psychological barriers in the road to sustainable development: Evidence from public sector procurement. Public Administration, v. 89, n. 2, p. 493-521, 2011. https://doi.org/10.1111/j.1467-9299.2010.01893.x

Rio de Janeiro. Decreto no 46.966, de 11 de março de 2020. Dispõe sobre as medidas para enfrentamento da emergência de saúde pública de importância internacional decorrente do coronavírus, e dá outras providências. Disponível em: <https://www.legisweb.com.br/legislacao/?id=390644>. Acesso em: 01 abr. 2020. 
Rubio, D. M.; Berg-Weger, M.; Tebb, S. S.; Lee, E. S.; Rauch, S. Objectifying content validity: Conducting a content validity study in social work research. Social Work Research, v. 27, n. 2, p. 94-105, 2003. https://doi.org/10.1093/swr/27.2.94

Sancho J. M. (Org.). Para uma tecnologia educacional. Porto Alegre: Artes Médicas, 1997.

Santos, R. S.; Foresti, L. F.; Santos Neto, A. M. V. Guia de compras públicas sustentáveis para administração federal. Brasília: UNILA, 2010. Disponível em: <https://www.unila.edu.br/sites/default/files/files/cartilha-compras-sustentaveis.pdf>. Acesso em: 20 jan. 2019.

Souza, T. F.; Arribard, P. T. B.; Frastrone, T.; Cracco, A. S.; Ribeiro, M. C. Gestão da Sustentabilidade: Um estudo de caso em uma empresa do setor energético. Lins: UNISALESIANO, 2009. Disponível em: <http://www.unisalesiano.edu.br/encontro2009/ trabalho/aceitos/CC35619583899.pdf>. Acesso em: 09 jan. 2019.

Zozzoli, J.-C. Marca e comunicação ambiental. Anais do XXXI Congresso Brasileiro de Ciências da Comunicação, Natal, Intercom, p. 1-15, 2008. 